\title{
Malformación arteriovenosa renal congénita: utilidad de la resonancia magnética para el diagnóstico y abordaje endovascular
}

\section{Congenital renal arteriovenous malformation: the value of magnetic resonance imaging for dignosis and intravascular management}

\section{Sr. Director:}

Presentamos el caso de un varón de 40 años, con antecedentes de crisis renoureterales, que acudió al Servicio de Urgencias por dolor lumbar derecho, hematuria intermitente y mala respuesta al tratamiento analgésico.

La radiografía de abdomen no mostró imágenes sugerentes de litiasis. Sin embargo, la ecografía del aparato urinario evidenció un aumento del tamaño del riñón derecho (RD) en relación con ureterohidronefrosis grado III/IV, sin imágenes de litiasis. Ante la persistencia del dolor se colocó una nefrostomía urgente. Esta maniobra provocó la aparición inmediata de hemorragia severa a través del tubo de nefrostomía, precisando su retirada y la transfusión de concentrados de hematíes.

Durante el ingreso hospitalario se solicitó una tomografía computarizada abdominopélvica para un estudio más exhaustivo. En ella se observó la existencia de 4 imágenes nodulares indeterminadas, con una densidad similar a la cortical, tres en la mitad superior del riñón en relación con la médula y una cuarta en la mitad inferior, en contacto con el seno renal, cuyas medidas fueron: $1,3,4,3$ y 2,8 cm, y aunque se confirmó el aumento de tamaño del RD no pudo hacerse lo mismo con la dilatación del sistema excretor.

En una resonancia magnética (RM) posterior, las estructuras varicosas del hilio renal muestran "vacío de señal", característico de sangre en movimiento en secuencias T2, y que tras la administración de contraste presentan intenso realce en la fase arterial con rápido relleno de la vena renal derecha, todo ello congruente con malformación arteriovenosa (MAV) congénita del RD con fístula arteriovenosa asociada (fig. 1). El

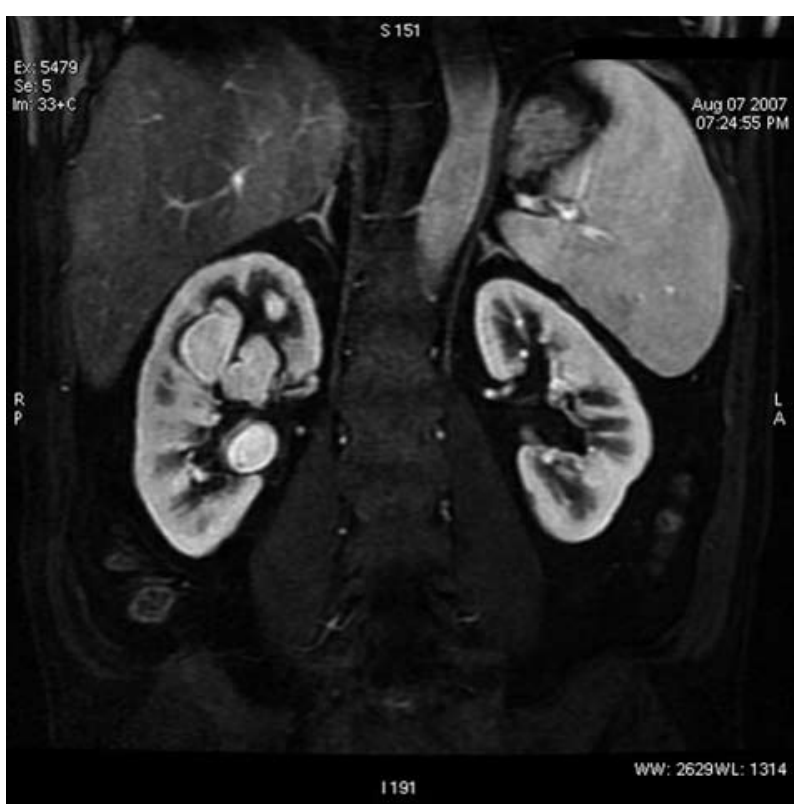

Figura 1 - Resonancia magnética que muestra relleno de las cavidades con contraste paramagnético en secuencias T1.

ecodoppler renal sirvió como estudio dinámico para corroborar el diagnóstico.

Se realizó una arteriografía, previa a la embolización, en la que se visualizaron 4 ovillos vasculares en el seno renal derecho, una fase nefrográfica opacificada en el RD y un relleno 


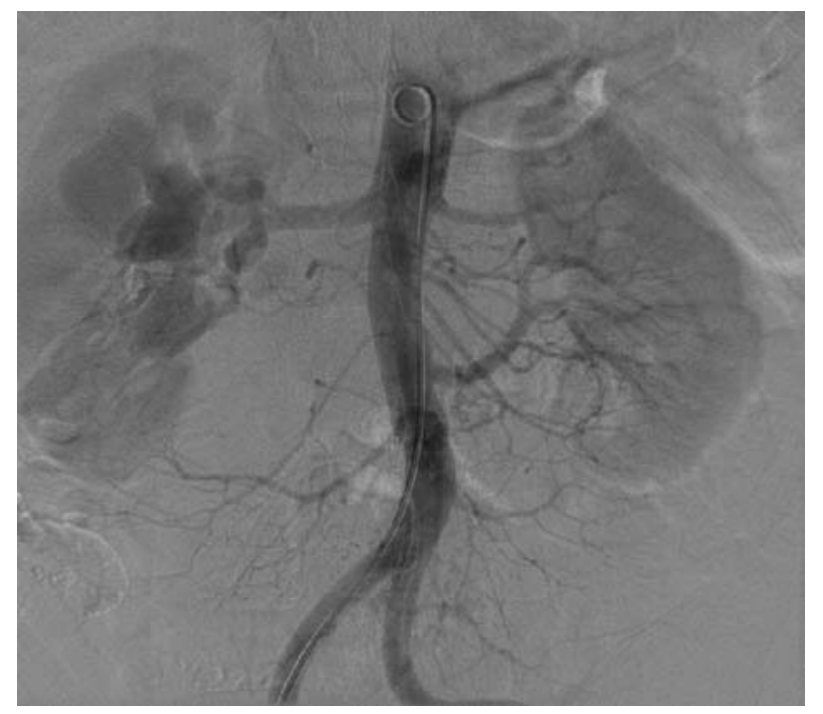

\section{Figura 2 - Aortografía. En el riñón derecho hay 3 ovillos vasculares, fase nefrográfica poco opacificada y relleno precoz de vena cava inferior, y dos arterias renales en el riñón izquierdo.}

precoz de la vena cava inferior, hallazgos todos ellos característicos de MAV del riñón (MAVR). Mediante un microcatéter se colocaron dos coils de Nitinol en el segmento superior y un tercer microcoil en el segmento inferior, consiguiéndose así la desaparición total del shunt arteriovenoso (fig. 2).

En los días siguientes a la embolización percutánea el paciente experimentó hipertensión arterial (HTA) y un síndrome de postembolización con febrícula, dolor severo en el costado y leucocitosis, que se trató con antibioterapia intravenosa, analgesia y reposo. Al alta el paciente estaba asintomático, con creatinina normal, pero con persistencia de la HTA.

Las MAVR constituyen una rara entidad clínica ${ }^{2-4}$. Fue Varela, en 1923, el primero en describir su existencia ${ }^{1}$.

Su prevalencia estimada es inferior al 0,04\% ${ }^{5} \mathrm{y}$, sin embargo, su incidencia va en aumento a consecuencia del incremento en el empleo de técnicas de diagnóstico por imagen ${ }^{6}$.

Las MAVR congénitas (20-25\% del total) se pueden diagnosticar a cualquier edad, aunque suelen manifestarse entre los 30 y 50 años ${ }^{3,4}$. Son más frecuentes en el RD y en la mujer $(2: 1)^{3}$. Se localizan por orden de frecuencia en el polo superior (45\%), tercio medio (30\%) y polo inferior $(25 \%)^{4}$. Pueden aparecer formando parte de diversos síndromes hereditarios, como Sturge-Weber y Klippel-Trenaunay ${ }^{2}$. Característicamente tienen una morfología cirsoide, con nidos tortuosos y múltiples comunicaciones arteriovenosas a nivel segmentario e interlobar. Están constituidas por vasos displásicos (ausencia de lámina elástica) subepiteliales localizados a nivel pielocalicial $^{7}$. Nuestro caso pertenece a este grupo de MAVR.

Para hacer el diagnóstico es fundamental la sospecha clínica y un exhaustivo diagnóstico diferencial de la hematuria. La radiología simple de abdomen no aporta ningún signo característico, salvo en aquellos casos en los que la fístula se asocia con un aneurisma calcificado ${ }^{4}$
La ecografía convencional es de poca utilidad. Las imágenes saculares y anecoicas localizadas al nivel del seno renal dan lugar a confusión con una hiliosinoquistosis renal o con ectasia de la vía ${ }^{2}$, como ocurrió en nuestro caso. Es necesario una ecodoppler para cuantificar el flujo y confirmar la existencia de shunt a nivel de dichas saculaciones ${ }^{2,7}$.

La RM puede identificar, en secuencias T2, "vacío de flujo" a nivel de las cavidades fistulosas, determinando así indirectamente la existencia de sangre en movimiento. En secuencias T1 con gadolinio dichas cavidades se rellenan precozmente de contraste, confirmándose así la comunicación arteriovenosa. Este fenómeno aparece con total nitidez en nuestro caso y fue clave en el diagnóstico por imagen de MAVR.

Según la literatura, la arteriografía muestra una serie de signos característicos que permiten el diagnóstico definitivo de MAVR, tales como el ovillo cirsoide, el relleno inmediato de las venas renal, gonadal y cava, y una fase nefrográfica poco opacificada ${ }^{4}$, hallazgos todos ellos presentes en nuestro caso.

La arteriografía y posterior embolización parecen, en la actualidad, la primera elección de cara al tratamiento. No obstante, la elección terapéutica varía según la clínica, el débito de la fístula y los medios disponibles en cada centro. En aquellos casos asintomáticos y fístula arteriovenosa de bajo débito la observación es la actitud inicial. Por tanto, trataremos los casos en los que haya repercusión hemodinámica, HTA mal controlada, aumento progresivo del tamaño de la fístula y hematuria recidivante o persistente. La cirugía queda reservada para los casos en los que el débito de la fístula sea elevado, afectando a grandes vasos (fístulas extrarrenales) y para los casos en los que la oclusión percutánea haya fracasado ${ }^{8}$.

El abordaje endovascular es una opción mínimamente invasiva y muy selectiva, cómoda para el paciente y con complicaciones poco frecuentes, consiguiéndose así disminuir el tiempo de hospitalización y los costes. Entre las complicaciones descritas en la literatura se encuentran la HTA, transitoria en la mayoría de los casos, y el síndrome de postembolización ${ }^{4,7,9}$, ambas presentes en nuestro paciente. En fístulas de alto flujo que involucran vasos principales, la recanalización de la fístula y la migración del material de embolización pueden ocurrir, dando lugar a trombosis venosa profunda, tromboembolismo pulmonar, necrosis cutánea e infarto colónico ${ }^{2,8,10}$.

En conclusión, en nuestro caso la RM fue clave para el diagnóstico de MAVR, y consideramos que el abordaje endovascular en casos seleccionados constituye una excelente opción terapéutica para el tratamiento de las MAVR.

\section{B I B L I O G R A F Í A}

1. Varela MC. Aneurisma arteriovenoso de los vasos renales y asistolia consecutiva. Rev Med Lat Am. 1923;14:32-44.

2. Pereira Arias JG, Ullate Jaime V, Pereda Martínez E, Gutiérrez Díez JM, Ateca Díaz-Obregón R, Ramírez Rodríguez MM, et al. Aneurisma cirsoide renal: una rara causa de hematuria severa. Arch Esp Urol. 2007;60(5):589-93.

3. Cabello Padial J, Soler Fernández JM, Murillo Mirat J, Herrera Puerto J, Zapata Blanco J. Fístula arteriovenosa renal 
congénita tratada mediante embolización. Arch Esp Urol. 1994;47(5):523-5.

4. Domínguez Bravo C, Soler Fernández JM, Poveda Pierola A, Asuar Aydillo S, Laguna Álvarez E, Caballero Gómez M, et al. Herrera Puerto. Fístulas arteriovenosas renales. Actualización y presentación de un nuevo caso. Actas Urol Esp. 1991;15:46-54.

5. Cho KJ, Stanley JC. Non-neoplasic congenital and acquired renal arteriovenous malformations and fistulas. Radiology. 1978;129:333.

6. Mora M, Machuca J, Cisneros J, Martínez Piñeiro JA. Fístulas arteriovenosas intrarrenales. Arch Esp Urol. 1987;40:12.

7. Crotty KL, Orihuela E, Warren MM. Recent advances in the diagnosis and treatment of renal arteriovenous malformation and fistulas. J Urol. 1993;150:1355-9.

8. Osawa T, Watarai Y, Morita K, Kakizaki H, Nonomura K. Surgery for gigant high-flow renal arteriovenous fistula: experience in one institution. BJU Int. 2006;97:794-8.
9. Sala Barange J, Maroto Genover JM, Rovira Rius JM, Rives Ferriol A, Carretero González P. Fístula arteriovenosa renal como causa de hematuria. Arch Esp Urol. 1987;40(3):143-7.

10. Ramírez Zambrana A, Lavalle Martín F, Zapata Blanco J, Mateos Blanco J, Toledo Serrano M, Molina Suárez JL. Fístula arteriovenosa renal congénita. Actas Urol Esp. 2009;33(6):696-9.

N. Miranda Utrera*, M. Pamplona Casamayor, F. Guerrero Ramos y O. Leiva Galvis Servicio de Urología, Hospital Universitario 12 de Octubre, Madrid,

España

${ }^{*}$ Autor para correspondencia. Correo electrónico: natipuchi@hotmail.com

(N. Miranda Utrera) 